\title{
Purification of Water by the Ultra-Violet Rays"
}

\author{
Principles Underlying the Most Recent System for Destroying Germ Life
}

By M. von Recklinghausen, Ph.D.

IT is a matter of common knowledge nowadays that the ultra-violet rays have a strong bactericidal power. Within the last few years this power of annihilating microbes by ultra-violet rays has been applied for freeing water of germs and a new industry has sprung up which produces water purifiers that make use of this new principle to sterilize water for drinking and othe purposes. As this system is being applied successfully to lare water plants, it is of interest for the profes-. sional water engineer to be fully inform fon the prof ciples underlying this most recent system of water purification.

The treatment of water by artificial light sources for the purpose of destroying its germ life dates back to

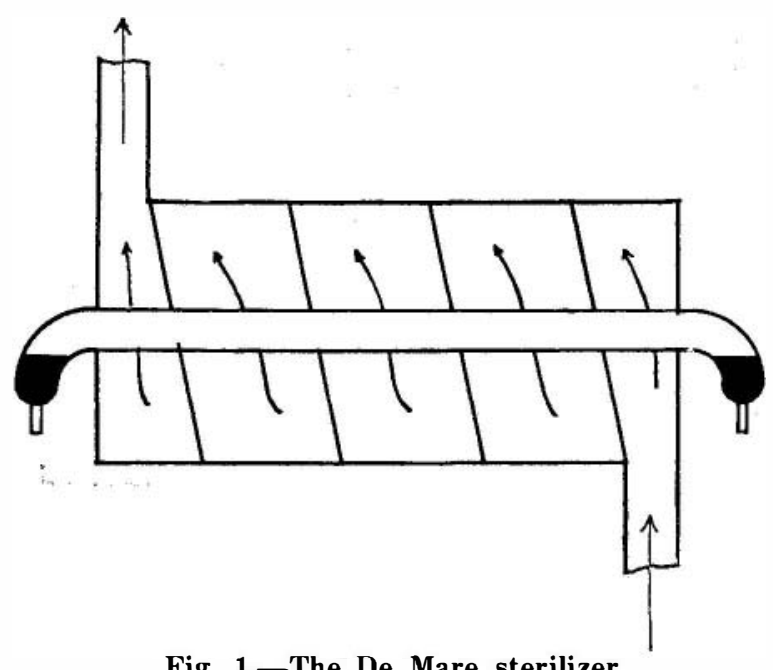

Fig. 1.-The De Mare sterilizer.

Downs and Blunt (1878). They found that the shorter the wave-lengths of the light the better the bactericidal action; and they were corroborated in this later on by Declaux, Arloing, Roux, Geissler, and others. We ow to Duclaux the theory that sunlight is the most commo and cheapest disinfectant known.

Marshall Ward (1892) completed these important studies by analyzing the effect of arc spectra thrown studies by ar of on infected agar plates; wherever they violet, and particularly by ultra-violet rays, they were disinfected and did not develop colonies. This English
scientist sterilized Thames water by placing it in a tank equipped with a quartz window and submitting it to the rays of an arc lamp. This was proposed agai later on by Lambert.

The first complete analysis of this bactericidal phe

* Paper read before the American Water Works Association Annual 'Convention at Philadelphia, and published in its Journat.

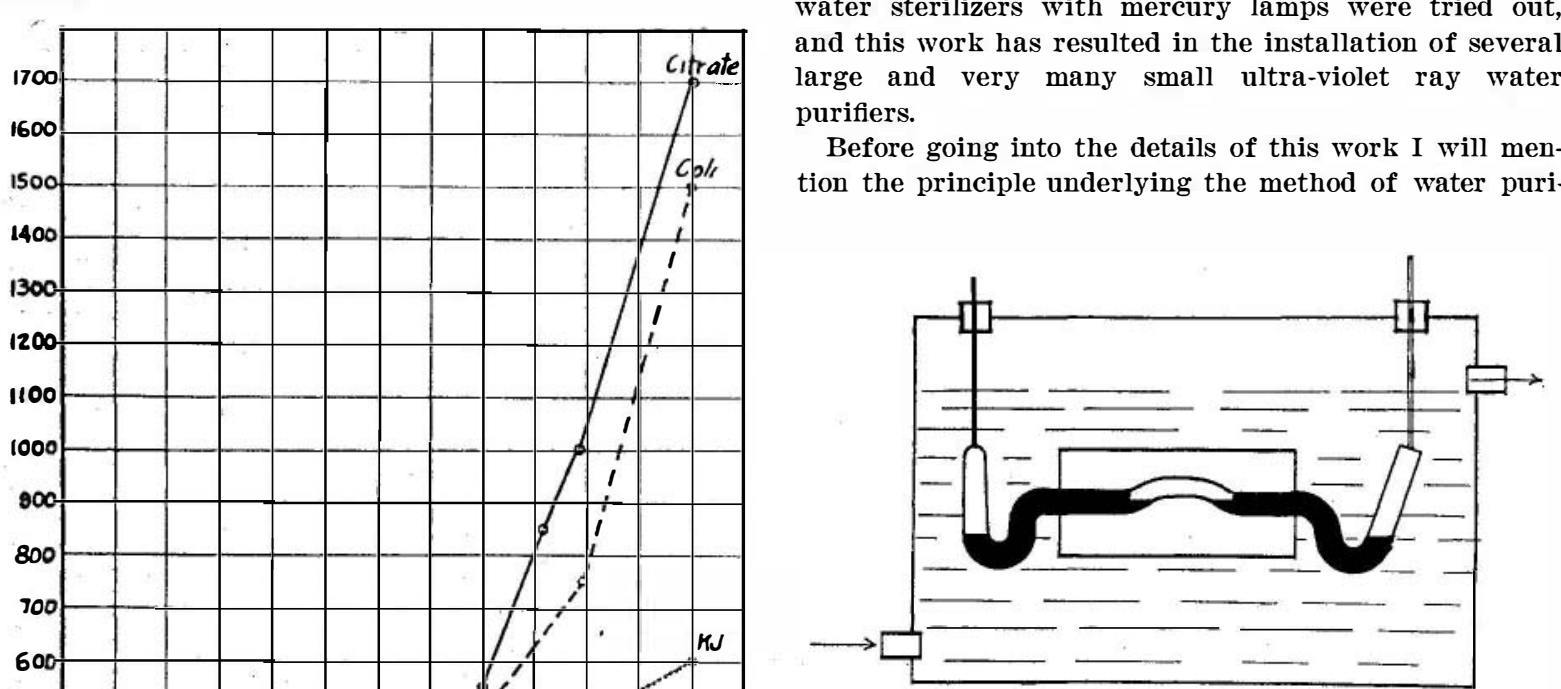

Fig. 5.-The Quartzlampen Gesellschaft.

fication by ultra-violet rays. We know from experiments that germs exposed directly to and at a very short distance ( $1 / 2$ to 1 inch) from a powerful source of ultra-violet rays, such as we use in a modern sterilizer, are killed within a small fraction of a second, in some cases one-twentieth of a second being sufficient

We therefore have to attend to two things: first, to an economic illumination of water with ultra-violet rays, and second, to make sure that every microbe contained in the water will be really led through the illuminated zone.

If we consider the latter point first, we come imme- ad, however, to await the arrival of really powerfu tically as a bactericidal agent for the purification of

This new source of ultra-violet rays was the mercury ts origin to the or of resulting in the well-known Cooper Hewitt illuminating replaced by quartz glass, that is to say, fused roc crstal, we obtain a container which allows the greatest ury arc to be sent out from the lamp.

The first to propose the adoption of the mercury arc for the purification of water was De Mare. His sterilizer consisted of a lamp around which the water fiows
in a circular path (Fig. 1). Some years later, and in a circular path (Fig. 1). Some years later, and water sterilizers with mercury lamps were tried out, diately to the conclusion that nothing must be in the water to intercept the rays, that is to say, there must not be any suspended matter in the water in the shadow of which the germ would be protected from the rays emitted by the lamp. SOURCE OF ULTRA-VIOLET LIGHT.

Practically every source of light emits some invisible ultra-violet rays together with the visible rays. This can be studied by dissolving the light into its components by means of a quartz glass prism. Our human eye will see on such a speetrum only the well known eye will see on such a speetrum only the well known below the red nor the wave-lengths beyond the violet; , however, the latter can be easily demonstrated by cer-
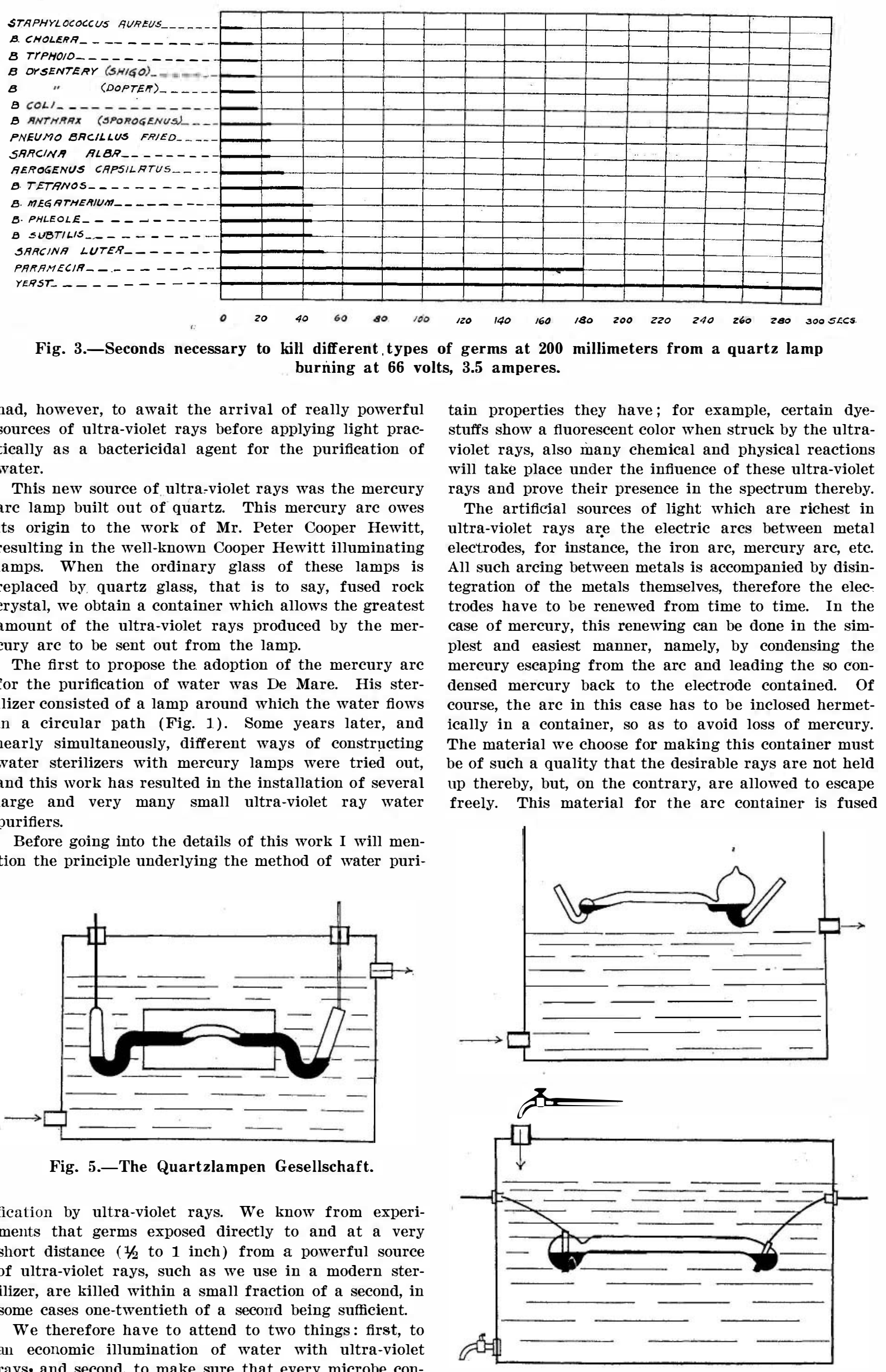

Figs. 6 and 7.- Upper figure: Apparatus used in experiments of Henri, Heilbronner, and Von Recklinghausen. Lower figure: Apparatus of Nogier. 
rock crystal, or more properly expressed, fused quartz. For a given amount of electrical energy put into this arc, such a quartz are lamp will attain a certain temperature depending upon its radiating capacity, that is to say, on its shape and surroundings. We have found that the amount of ultra-violet rays produced by such a quartz lamp is considerably more when running at a high temperature, than when it is run at a low temperature. The production of ultra-violet rays is, therefore, the more economical the higher the temperature of the lamp. This high temperature is obtained by raising the namely, about 800 deg. Cent., by the fact that quartz if maintained for a long time at a higher temperature will devitrify, becoming thereby more or less opaque to the visible and invisible rays emitted from the arc. As in a wate sterilizer we naturally want to approach the lamp as

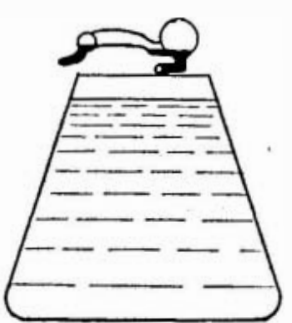

SECTION $A \cdot A$

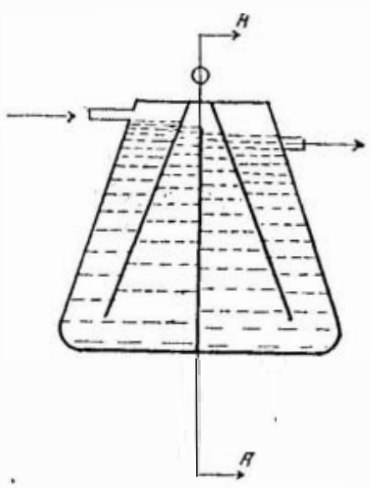

Figs. 8 and 9.-Experimental apparatus used by the writer.

close as possible to the water, we must be careful to consider what has just been said about temperature and prevent the water from cooling the luminous part, rendering it thereby inefticient in its production of ultraviolet rays.

PHYSICAL CHARACTERISTICS OF ULTRA-VIOLET LIGHT. The ether vibration can be distributed in four groups according to their wave-lengths, namely (1), the electric rays, (2) the infra-red rays, (3) the rays of the visible spectrum, (4) the ultra-violet rays.

Between the last electric rays and the first infra-red rays exists probably a group of still unknown qualities. All these rays travel at the same speed, namely, 300,000 kilometers per second. The wave-lengths are as follows: 1. Electric waves (Hertz, 1888) from several kilometers down to 3 millimeters

2. Infra-red rays (Herschel, 1800) from 300 down to $0.76 \mu{ }^{1}$

3. Visible rays (Newton, 1666) from $0.76 \mu$ down to 0.40

4. Ultra-violet rays (Ritter, 1802) from $0.40 \mu$ down to $0.10 \mu$.

We are interested to-day in that last named group, number 4, namely, the ultra-violet rays whose upper limit is more or less vague (Fig. 2). It is sometimes placed at $0.3969 \mu$; however, even shorter waves can be noticed by the eye, although not directly, but only by the fact that the crystalline in our eyes becomes fluorescent, giving thereby impression of gray on the retina. If people, therefore, have sometimes thought they were able to see ultra-violet rays, they really only saw thei own crystalline. The lower limit of $0.10 \mu$ of the ultra-

${ }_{1 \mu}=\frac{1}{1000}$ millimeter $=10.000$ Angström units.
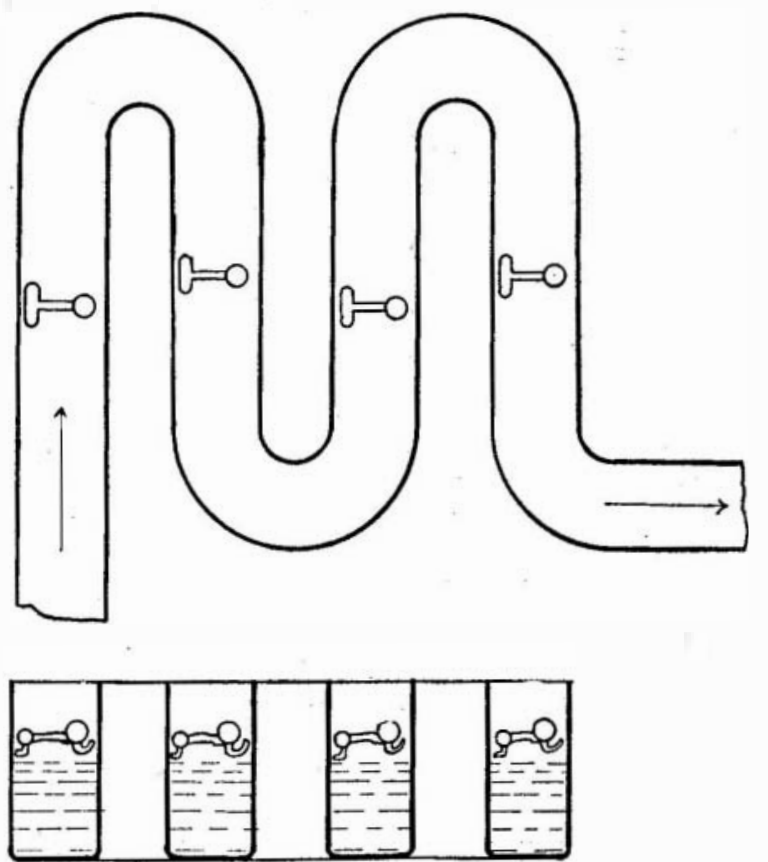

Fig. 10. - Large experimental apparatus designed to stir and circulate the water. violet rays was obtained by Schumann and Lyman by working in vacuum with fluorspar prisms. Howeve these very short wave-lengths do not come into consid eration in our case, because a few millimeters of air absorb completely the wave-lengths below $0.150 \mu$ an abser below 0.1850 ultra-violet from $0.2943 \mu$ down. This wave-length is therefore the shortest of the sun's waves reaching our eye, and therefore the ultra-violet contained in the sun' rays are only the wave-lengths between $0.40 \mu$ and $0.2943 \mu$

Quartz, the only material which we can apply for our lamps, absorbs practically everything below $0.20 \mu$; therefore we may say that from the ultra-violet ray efficiency point of view it does not matter very much whether a quartz lamp is surrounded by a thin layer of air or by vacuum. Glass absorbs ultra-violet rays to an enormous extent, as may be seen from the fact that the bactericidal power of a quartz lamp is cut down to $1 / 1,000$ if the lamp is surrounded by a glass tube.

$$
\text { BACTERICIDAL POWER OF ULTRA-VIOLET RAYS. }
$$

It was of interest to see whether different microbes had different resistivities against ultra-violet rays in the same way that they are different against disinfectants and heat, and we come to the astonishing result that they do not vary anything like as much. For instance, spores are often twenty times as resistant as the unprotected forms of germs against chemicals. We find that some are only 1.5 to 5 times as resistant against ultra-violet light as ordinarily unprotected water bacteria The table on page 10 (Fig. 3) shows a comparison of different types of germs in their resistivcomparison of different types of germs in their resistiv-
ity. In each case under similar conditions cultures were ity. In each case under similar conditions cultures were made and the free germs put in clear water, care being taken, however, to avoid clumps of bacteria and also to avoid the presence of the nourishing medium, for otherwise the germs wor

It has sometimes been thought that the bactericidal
a d It has sometimes been thought that the bactericidal
action of the ultra-violet rays was due to a small amount of hydrogen peroxide, which indeed forms itself by the exposure of water to the ultra-violet ray However, this formation is so minute that it is barely noticeable after ten hours' exposure of the water, and we can surely say that the bactericidal effect is not due to the action of the so-formed disinfectant but is a cal action of the ultra-violet rays on the germ. It is not likely that by the action of the rays, during such a short period, the entire bacteria should be chemically changed, coagulated, or otherwise mod fied, but it is more probable that some ferment, or similar product contained in the cell, is modified by the rays, and thereby poisons the system of the cell.

We have often been asked whether the germs struck by the light may not be simply stunned, and may survive again afterwards. In answer to this I will say that the methods of making the counts in Europe would enable one to find out whether there is any reviving. These counts extended over a period of usually fiftee days and never have shown any indication of revival. QUANTITOMETRY OF ULTRA-VIOLET RAYS.

The luminous power of light sources is usually measured by comparing them with standard lamps. The moment that the light one wants to measure has a color different from the standard lamp, great difficulties arise, different from the standard lamp, great difficulties arise,
based on the fact that we do not really compare the based on the fact that we do not really comp
two lamps physically, but only physiologically.

The difficulty of determining the ultra-violet candlepower of a lamp is far greater again, as we are not sensible to these rays at all. To get some idea of the strength of ultra-violet source we have therefore to create new means and units of comparison. Many different chemicals and physical reactions take place in the ultra-violet light. One may, therefore, base a measthe ultra-violet light. One may, therefore, base a meas-
ure of the ultra-violet candle-power on the speed and ure of the ultra-violet candle-power on the speed and
strength of such a reaction. The most typical and inost strength of such a reaction. The most typical and snost convenient reaction of this kind is the blackening of photographic paper. We have found that a mercury quartz lamp will blacken paper about four times as An ordinary sensitometer can be built embodying this An ordinary sensitometer can be built embodying this
principle. Another reaction of the ultra-violet rays may principle. Another reaction of the ultra-violet rays may
be considered by comparing the amount of fluorescence be considered by comparing the amount of fluorescence
produced by the lamps, but both of these me'ihods of produced by the lamps, but both of these me'ihods of measuring will only allow us to compare light souroes of similar composition. They do not give us what is really most interesting for us, namely, a mea:sure of the bactericidal power of a lamp, and we therefore thought it best to adopt a real biologic test for the measure of the abiotic strength of quartz lamps. There remains, therefore, nothing for us to do but to establish a standard source of ultra-violet, that is to say, a laboratory standard composed of a certain lamp which is so kept that it is most unlikely to change in candle-power, and compare the action of this lamp with the action of the lamp one wants to measure on one and the same cul. tures of germs. The way we proceed is as follows: We

make a culture of paramecies which are very similar in their sensitivity to ultra-violet rays as ordinary wate bacteria. As a matter of fact, they will stand about six times the exposure that bacterium coli will stand, as Fig. 3 shows.

The sensitivity of such a culture is determined by xposing a drop of it at a defined distance from the laboratory standard quartz lamp. Another drop of it is

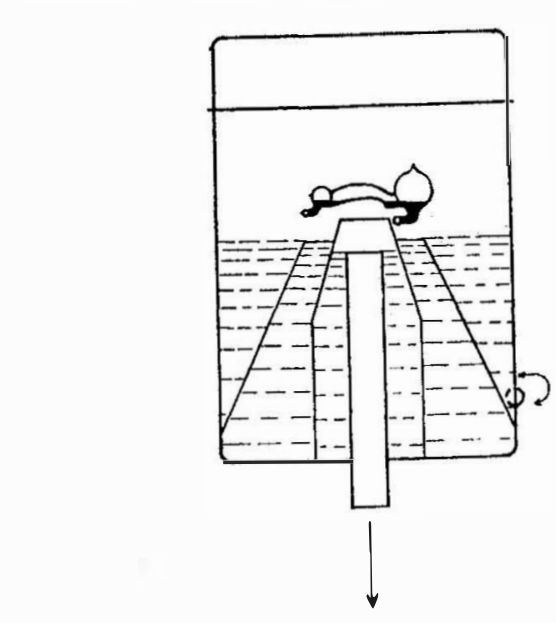

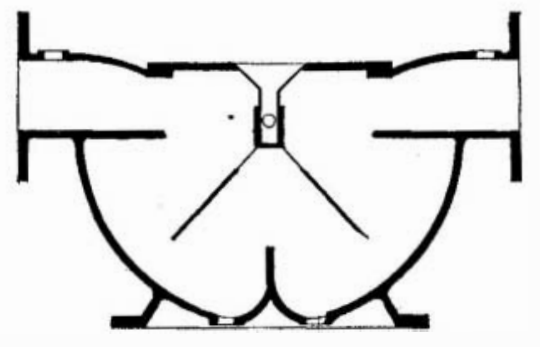

SECTION ON \&

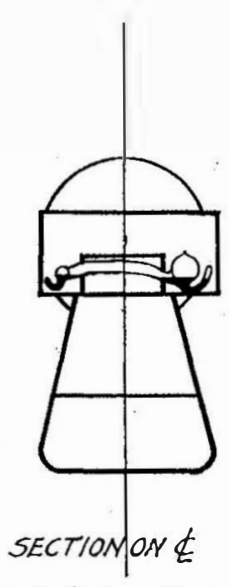

Figs. 11 and 12.-Typical apparatus that stirs water being treated between successive illuminations.

exposed at the same distance to the lamp one wants to measure, and the time necessary for killing gives the indication of the relative value of ultra-violet candlepower. We have chosen paramecias because they are easily observed under a microscope, having a rather violent motion while alive, and naturally no motion when dead. A few observations will, therefore, give us within a few minutes a definite idea of the lactericidal power one wants to measure.

I may say that we have checked figures so obtained with the effect on coli cultures, and can see thereby that we have a fairly safe process for determining by comparison the ultra-violet candle-power of a lamp.

With all that, we may say that the action on photographic papers is, in most cases, a precise enough indication of the ultra-violet candle-power, as may be see from Fig. 4.

It is natural that the electric characteristics of the lamps for these measures are checked up by the usua electrical instruments indicating the amperage and volt age of the lamp.

DEVELOPMENT OF THE STERILIZING APPARATUs

The experiments we made at the Sorbonne laboratory as well as the experiments of others working in thi field, were started by exposing polluted water in containers to the light of the quartz lamps. These experiments allowed us to get data for the construction of terilizing apparatus where the water was circulating continually through the illuminated zone.

As examples for the simplest form of apparatus, I will

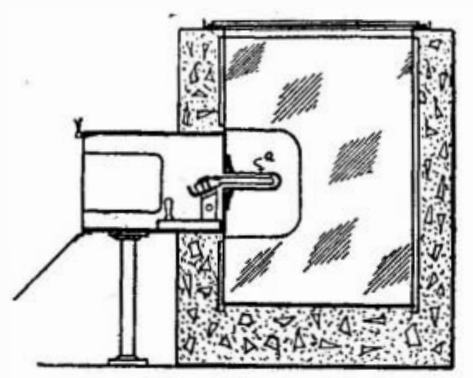

SECTION $A-A$

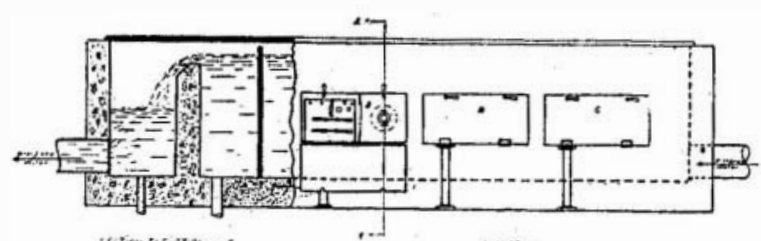

Figs. 13 and 14.-Showing pistol lamp applied to flunies 
mention the sterilizing tank which we used in our preliminary experiments (Fig. 6), and Nogier (Fig. 7) and the Quartzlampen Gesellschaft (Fig. 5). In all of these experiments the water was simply passed in a straight fiow underneath or around the source of the ultra-violet light. We found the results with this type of apparatus to be irregular, and came to the conclusion that this was due to the fact that the water, although clear, still contained some microscopic susalthough clear, still contained some microscopic susprenled matter which, when the water was
straight, would allow microbes to be shielded.

We therefore considered it advantageous to expose the water a second and third time to the light, after having stirred it between illuminations. In this way we expected to turn over such microscopic particles and have them therefore exposed on all sides to the action of the lamps. A typical case of such apparatus was shown in the design Figs. 8 and 9 . The water in similar apparatus of considerably larger size (Fig. 10) similar apparatus of considerably larger size (Fig. 10)
flowed through four illuminated zones, and stirred itsel flowed through four illuminated zones, and stirred itself up through its fiow around the bends of the canal between the luminous zones. The results were very satisfactory, as we obtained sterilization from about 5,000
germs per cubic centimeter down to less than 10 per cubic centimeter, the consumption of electric energy for the lamps being at the rate of 144 kilowatt hours pe million gallons. The submitting of the water to succesmillion gallons. The submitting of the water to succes-
sive illuminations, and stirring up during illumination sive illuminations, and stirring up during illumination,
can also be done with a single lamp by so arranging baffles that the water is led several times toward an away from the source of the light (Figs. 8 and 9). Typical apparatus of this kind is shown in the B2 (Fig. 11) and C3 (Fig. 12) apparatus. The former apparatus, B2 type, uses only perhaps one fourth of the light emitted by the lamp. However, the apparatus is easy to handle and of a small size

The C3 apparatus was constructed in a somewhat different way, with a view of using a greater proportio of ultra-violet. The lamp was protected from contact with the water by inserting it into a chamber fitte with quartz windows, which chamber was submerged in the tank containing the water. Three contacts of the water with the light are obtained in this apparatus.

It was desired to so construct the lamps that practically all their light could enter into the water and exert its sterilizing action. The so-called pistol lamps which have a U-shaped luminous tube (Fig. 15) allow this to be realized, the luminous part being inserted into quart tubes, which protect them from contact with the water (Figs. 13 and 14). Such pistol lamp equipments can be inserted into fiumes through which the water fiows, and give the water several successive illuminations (Figs give the water several successive illuminations (Figs.
13,14 ). The necessary stirring action in the water is $13,14)$. The necessary stirring action in the water is
obtained by bafte plates placed in the lamp axis whereby fairly violent stirring is taking place near the amp.

The largest lamp unit made so far is the 500-volt 2.5 amperes, pistol lamp, and a maximum number of te such lamps are inserted into a single fiume.

As to the depth of the water in sterilizing apparatus, theoretically the best will be a very great depth of the water. We have observed strong bactericidal action even through three feet of water, the ratio being practically, as may be expected, inversely as the square of he distance, that is to say, for instance, one ninth of bactericidal action at three times the distance. Calculation and practice have shown us that it is good to provide, if possible, two feet depth of water in larger apparatus. Of course in apparatus working with water which is highly colored this depth may be reduced, as otherwise it would make the apparatus unnecessarily otherwise it
cumbersome

The whole system having been developed abroad, it is only natural that there are considerably more such installations in Europe than in this country. Small installations are used for producing water for drinking and surgical purposes in hospitals, schools, etc., also for bottling purposes. The first large installation of a $\mathrm{C} 3$ apottling purposes. The first large installation of a $\mathrm{C}$ running since November, 1910, in a suburb of Rouen. The hygienic results from this plant are very satisfac tory, typhoid in the district fed with the water from this plant being extinct, while it exists still in the surrounding districts which use similar water without ultra-violet ray purification.

A plant with four 220-volt pistol lamps has been running for over a year in Saint Malo sterilizing the wate at a rate of 750,000 gallons per twenty-four hours.

Many C3 apparatus are running in France, in some cases two being run in series, with always very gratify ing results. The largest sterilizing unit composed of a flume with ten 500-volt pistol lamps is sterilizing the water for the city of Luneville, France (Fig. 16). This supply consists of $1,500,000$ gallons of river water and 375,000 gallons of spring water. The water in this case, which in its raw state is extremely muddy and rich in colloidal matter, is filtered through a rough and slow sand filter without the addition of coagulants, at a rate of about 7,000,000 gallons per acre. In case of a biological filtration this type of water would have to be filtered at the rate of 2,500,000 gallons per acre

On account of some turbidity, and also an often deep color of the filtered water (up to $40 \mathrm{U}$. S. standard) this plant has an exceedingly high current consumption namely, 130 kilowatt hours per million gallons: during most of the time two thirds of this consumption would ample.

The first application of the ultra-violet ray system for terilizing water on a large scale in this country was

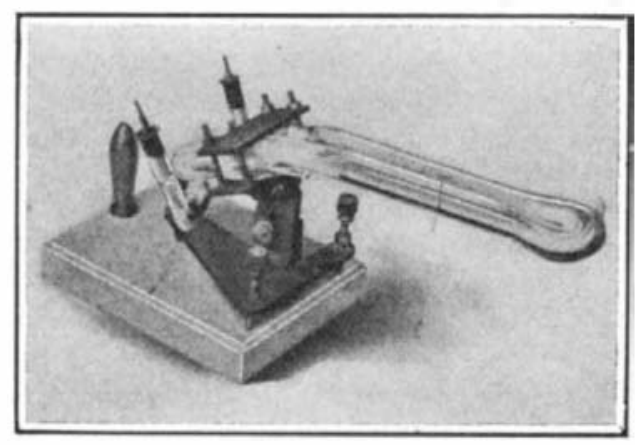

Fig. 15.-The pistol lamp.

started recently in New York, where the water of a swimming pool is continually being circulated through a rapid filter and a sterilizing flume, equipped with two 220 -volt pistol lamps, the fiow being about 5,000 gallons an bour.

As mentioned in the theoretical part, the ultra-violet rays must be able to strike the microbe; where any suspended matter is interposed, the bactericidal action cannot take place, because the microbe is in the shadow. It is certain therefore that only clear water can be submitted to the ultra-violet ray treatment for its sterilization. That is to say, in most cases it is necessary to filter the water before the same is submitted to the action of the lamps. As color in solution will absorb ultra-violet rays to a certain extent, it is evidently better to also free the water from coloring material before submitting it to the rays.

The question of suspended matter in the water is of somewhat greater importance. Sometimes water with little suspended matter may be more difficult to sterilize than water with far more suspended matter. The reason for this is that it will depend not only on the size and quantity of the suspended matter, but also on its biological quality. That is to say, suspensions of purely mineral nature, which do. not inclose any microbes, and to which few microbes are attached, handicap the sterilization of the water very much less than suspended particles in similar water which are heavily covered with microbes, and particularly so if microbes are inclosed in these particles, because it is then most likely

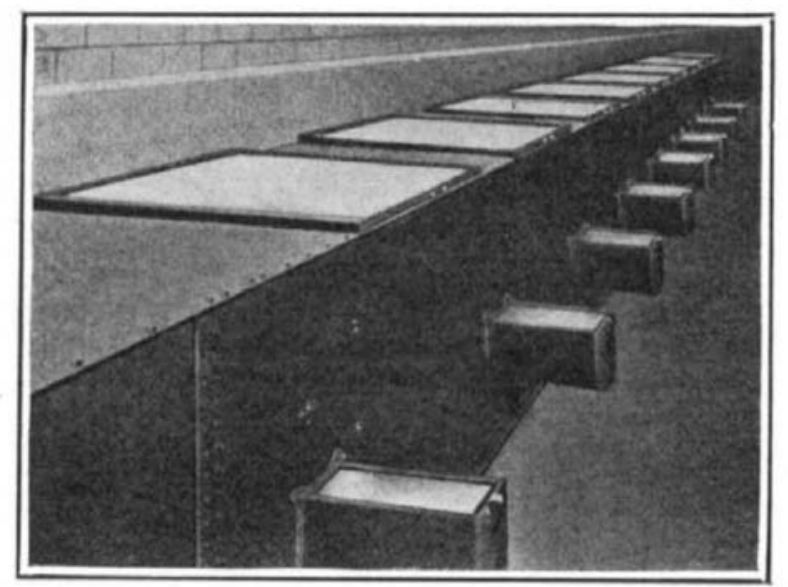

Fig. 16.-Sterilizing apparatus at Luneville, France, in which ten pistol 500-volt lamps operate on one $1,500,000$ gallons of water a day.

that a repeated exposure to the rays will be necessary to penetrate to the inclosed germ life.

If the suspended matter is of smaller size than the germs, like colloidal clay, we expect such turbidity to act more or less like color in solution, demanding simply more illumination than clear water. Experiments made with one of the $\mathrm{B} 2$ apparatus on water showing up to 20 turbidity seem to prove that such fine turbidity does not.handicap sterilization very much.

From the economical point of view, the condition in which the water is submitted to the rays is evidently of great importance for the ultra-violet rays sterilization system. Physically ideal water, that is to say, water without suspended matter, turbidity of color, will need very little power in ultra-violet rays to become need very little power in ultra-violet rays to become
sterile. In large plants 50 kilowatt hours per million gallons will produce a great over-dose in ultra-violet.
Smaller installations are being equipped usually with charcoal or paper filters. In large plants naturally the filter question is an engineering proposition; so is the question of choice between mechanical and sand filters. It seems that if the latter are chosen they can be speeded up to a great extent as against the speed for biological filtration and still give a physically pure enough water for ultra-violet ray treatment as, for example, the Luneville plant where the water is filtered practically at three times the rate of biological filtration for that particular kind of water. In other plants the filtration has been speeded up to $10,000,000$ gallons to $12,000,000$ gallons per acre, and we even tried with fair success $25,000,000$ gallons per acre, followed by ultra-violet ray treatment. This will, naturally, always depend on the filtrability of the water.

Operating costs will vary with the size and the running hours of the plant, and the coefficient of safety one wants to give to the ultra-violet ray treatment. According to the quality of the water, I expect in large plants the current consumption will vary between 50 and 125 kilowatt hours per million gallons, allowing for a large safety coefficient. The labor charges are negligible, as the apparatus only needs an occasional cleaning and starting of lamps. Apart from this, the lamps have to be repumped and repaired from time to time.

In any engineering proposition we always try to adopt as large a safety coefficient as possible. If we rely on chemicals to disinfect our water, we must work right close to and sometimes even over the limit of the amount which will not make itself objectionable by producing taste and odor in the water.

In the ultra-violet rays we have a system where we may choose our safety coefficient as high as ever we like that is to say, we may over-dose our sterilization as much as we want without creating any objectionable features in the water, like taste and odor.

\section{The Photokaleidograph*}

\section{An Apparatus for the Production of Kaleidoscopic} Pictures.

THE kaleidoscope has not been used exclusively as a plaything for children. It has furnished many patterns for woven fabrics, embroideries, carpets and oilcloths. The combination of the kaleidoscope with the photographic camera has often been attempted, but with ittle success.

In the last few years my attention has been drawn to these matters in the course of my professional work for the Carl Zeiss Optical Company. We received a commission to construct a kaleidoscope of precision. After overcoming certain difficulties I succeeded in producing the instrument herewith illustrated, which can be used either for direct observation or for photographic reproduction of the kaleidoscopic patterns.

In this instrument a solid glass prism takes the place of the two inclined mirrors of the old Brewster kaleidoscope. The faces of the prism are cut accurately to the prescribed angle, polished and silvered. The prism is protected from injury by covering it with strips of black glass, cemented to its faces. The ends of the prism are cut perpendicular to the axis and polished, and the prism is inclosed in a brass tube, from which its ends only protrude.

The tube is mounted vertically above the horizontal photographic plate, measuring 13 by 18 centimeter (about 5 by 7 inches). The photographic lens is secured to the lower end of the tube. The distance of the tube from the photographic plate is adjusted to produce a sharp image, and this distance is fixed by means of a stop-ring, surrounding the tube. Several tubes of exactly the same diameter, containing prisms of different sizes and angles, are provided, and can easily be interchanged.

The object, which is to produce the photographed kaleidoscopic pattern by internal reflection from the faces of the prism, is itself a photograph on glass, which is pressed lightly, with the film side down, on the upper end of the prism, to which a drop of oil has been applied. The picture is usually larger than the sectional area of the prism, but only the part included in that area is reproduced and repeated on the photographic plate beneath. The illumination is furnished by a mercury vapor lamp, provided with a ray filter which transmits only the light of one of the violet mercury lines.

For the observation and selection of the patterns an inclined plane mirror is placed between the lens and the plate holder. This mirror refiects the kaleidoscopic image to a ground glass screen which can be observed by several persons at once. If it is decided to photograph the pattern, the mirror, which is mounted on horizontal axis, is turned into a position in which it excludes light entering through the ground glass and allows the rays from the lens to fall on the photographic plate. The raphic plate. The mirror is fastened in this position 